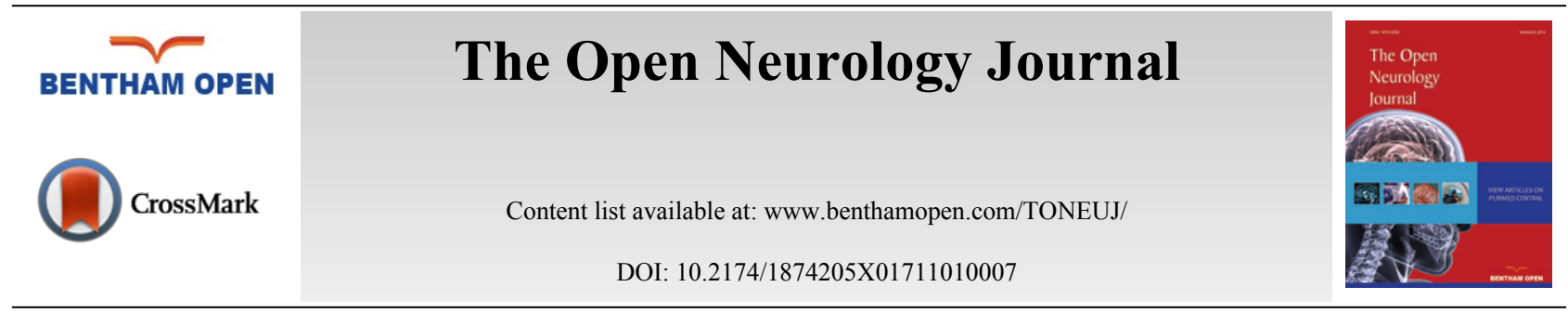

CASE REPORT

\title{
Case Series Using Montelukast in Patients with Memory Loss and Dementia
}

\author{
Spencer I. Rozin ${ }^{*}$ \\ Rozin Internal Medicine - United States
}

\begin{abstract}
Cognitive decline and dementia are a growing problem as the population ages. Effective therapies to prevent and treat these problems are limited. Neuro-inflammation has been suggested as a cause of dementia [1]. Montelukast is a leukotriene receptor antagonist used to treat seasonal allergies and asthma. It acts as a cysteinyl leukotriene (CysLT1) receptor antagonist blocking the action of leukotrienes and decreasing inflammation [2]. Animal studies have shown that administering Montelukast improves memory function [3]. This case series of patients in a private Internal Medicine practice between 2013-2014 used Montelukast in patients with various levels of memory impairment and dementia. Patients were given Montelukast $80 \mathrm{mg}$ daily in 4 divided doses every 2-3 hours. Memory impaired patients had subjective improvement in the memory and recall. Patients with dementia were noted by family members to be less agitated, but had no memory improvement at the doses used. Montelukast may be useful to treat memory impairment and dementia. Long term use might act as a prophylactic to prevent dementia.
\end{abstract}

Keywords: Alzheimer's, Cognitive impairment, Dementia, Memory loss, Montelukast.

\section{INTRODUCTION}

Cognitive impairment and Alzheimer's dementia are expected to significantly increase as the population ages. Current therapies have limited utility in preventing and treating these diseases. Alzheimer's disease is thought to currently affect 5.1 million Americans of age 65 or older, with a 2:1 ratio of women to men being affected. The affected population may increase almost 3 fold by 2050. Out of the top 10 causes of death, Alzheimer's ranks the $6^{\text {th }}$ and is the only one that is not preventable. The cost to provide care for patients with Alzheimer's by the year 2050 is expected to be close to $\$ 1.1$ Trillion [4]. Having a safe, effective drug to reverse the cognitive impairments of dementia would have a dramatic effect on the lives of millions of patients. If the drug also prevented the neurological changes that cause dementia, this could benefit tens of millions more people.

\section{METHODOLOGY}

All patients or medical agents gave oral consent to participate in this case series. Patients were treated with Montelukast $20 \mathrm{mg}$ orally upon arising and then $20 \mathrm{mg}$ every 2-3 hours for a total of 4 doses daily following protocol outlined in the USPTO Patent Number: US8575194 filed by Jack William Schultz [5].

All patients had either a Mini Mental Status Exam (MMSE) [6] or Montreal Cognitive Assessment (MOCA) [7] prior to the treatment. Results were obtained by subjective response of patients or medical agents.

\footnotetext{
* Address correspondence to this author at the Rozin Internal Medicine, 721 Wellness Way, suite 220 Lawrenceville, GA, 30046 United States; Tel: 770-709-0900; Fax: 770-709-7444; E-mail: askdrrozin@drrozin.com
} 


\section{RESULTS}

\section{Patients Treated Without Knowledge of Medication Identity:}

Patients had memory problems, forgetfulness, and issues with word recall, problems with focus or concentration or feeling like being in a fog. All patients had MMSE scores 27-30/30.

Patient \#1 was a 69 year old (y/o) White male (WM)

Patient \#2 was a 65 y/o WM

Patient \#3 was a 69 y/o White female (WF)

Patient \#4 was a 52 y/o WF

Patient \#5 was a 56 y/o WF

Patient \#6 was a 69 y/o WM

All patients had significant subjective improvement in the symptoms within 24 hours of starting the medication and recurrence of symptoms 24-48 hours after discontinuation. One patient developed insomnia which resolved with dose reduction. No other side effects were reported.

\section{PATIENTS TREATED WITH KNOWLEDGE OF THE MEDICATION NAME AND NORMAL USE}

\section{Patients with Suspected Memory Impairment by Report and Testing}

All had memory problems, word recall issues, and problems in staying focused. Family also reported declines in the memory. Patients had MMSE exam scores 29-30/30.

Patient \#7 was a 70 y/o WM

Patient \#8 was a 54 y/o, Black male

Patient \#9 was a 75 y/o WM improved with $20 \mathrm{mg}$ dose in AM, but forgot to take other doses during the daytime. Improvement wore off after 2-3 hours.

These patients had significant improvement in the symptoms. The symptoms recurred in 24-36 hours of discontinuation of the medication. No side effects were reported in any patient.

\section{Patients with Dementia Who Had Agitation and Anxiety Symptoms}

All patients had MMSE scores 20-26/30.

Patient \#10 was an 85 y/o WF who was already on Namenda and PRN Xanax

Patient \#11 was an 86 y/o WM who was already on Namenda and Prozac

Both patients had very dramatic response with the resolution of anxiety, agitation and their families noted that the patients were more interactive. Patients had no significant memory improvement. No side effects were reported.

Patient \#12 was an 86 y/o WF who showed no improvement. She was previously intolerant to Aricept, Exelon and Rivastigmine.

\section{Patients with Dementia, Anxiety and Agitation Along with Other CNS Issues}

All patients had MMSE scores 23-25/30.

Patient \#13 was a 77 y/o WM with co-existent mild traumatic brain injury already on Namenda and Aricept

Patient \#14 was a 79 y/o WM with severe long lasting post-operative dementia already on Aricept and Ativan

Patient \#13 improved significantly and Patient \#14 showed mild improvement. No side effects were reported.

Patient \#15 Was an 85 y/o WF with MMSE 26/30. She declined Namenda and Aricept. Memory improved within 1 week of starting medication per patient and husband. No side effects were reported. MMSE follow up was 28/30 on medication.

Patient \#16 was an 84 y/o WM with a MOCA score of 18/30 on Razadyne 4 mg BID with worsening memory per 
patient and wife. He declined Namenda or higher dose Razadyne. The family noted improvement in patient's memory and he was less agitated on Montelukast, but due to frequent dosing schedule, he discontinued the medication after 2 weeks.

Patient \#17 was a 78 y/o WF with a MOCA score of 13/30 on Namenda10 mg BID and Aricept 10 mg daily with worsening memory per patient and family. The patient's agitation and anxiousness improved per family report.

\section{DISCUSSION}

This case series suggests that Montelukast may have significant potential to improve cognitive impairment and dementia. Montelukast is known to block the activation of the CysLT1 receptor [2]. Activation of CysLT receptors induces neuroinflammation. It has been shown to increase astrocyte proliferation and glial fibrillary acidic protein [8], response to acute neuronal injury after focal cerebral ischemia [9], and the activation of human traumatic brain injury and brain tumors [10] and induce astrocyte proliferation and death after oxygen-glucose deprivation [11]. Prior animal studies have suggested that use of Montelukast may decrease the central nervous system inflammation [12], and attenuate chronic brain injury after induced focal cerebral ischemia [13] and protects against quinolinic acid/malonic acid induced neurotoxicity [14].

In the rat studies $[3,15]$ the use of Montelukast was associated with improved neurocognitive function with the proposed mechanism showing improvement in neuroinflammation. These studies have used Montelukast doses up to 10 $\mathrm{mg} / \mathrm{kg}$ body weight. The use of higher doses than that used in this case series may show memory improvement in patients with dementia. Further studies with Montelukast in patients with cognitive impairment and dementia as well as in a trial of prophylactic use to prevent these illnesses should be done. The reuse of an older medication might speed the development of an effective medication for these devastating diseases and result in a new product that would be affordable to a huge population of patients.

\section{CONCLUSION}

The use of Montelukast in patients with cognitive impairment improved memory. Its use in patients with dementia led to lessened agitation, but the effect on memory improvement may be limited by the dose selection lower than that used in the animal studies.

\section{CONFLICT OF INTEREST}

The author confirms that this article content has no conflict of interest.

\section{ACKNOWLEDGEMENTS}

Declared none.

\section{REFERENCES}

[1] Daniela L. Krause and Norbert Muller Neuroinflammation, Microglia and Implications for Anti-Inflammatory Treatment in Alzheimer's disease Int J Alzheimer's Dis 2010. Article ID 7328069 pages.

[2] FDA, Montelukast. (Singulair, application number 20-830) Pharmacology Review. Available at: http://www.accessdata.fda.gov/drugsatfda docs/nda/98/20830_Singulair_pharmr.pdf

[3] Marschallinger J, Schäffner I, Klein B, et al. Structural and functional rejuvenation of the aged brain by an approved anti-asthmatic drug. Nat Commun 2015; 6: 8466. [http://dx.doi.org/10.1038/ncomms9466] [PMID: 26506265]

[4] Alzheimer's Association. Alzheimer's Association, Available at: http://www.alz.org/facts/

[5] Treatment methods of cognitive, emotional and mental ailments and disorders. US Patents US 8575194 B1, 2013. Publication date 11/15/2013

[6] Folstein MF, Folstein SE, McHugh PR. Mini-mental state. A practical method for grading the cognitive state of patients for the clinician. J Psychiatr Res 1975; 12(3): 189-98. [http://dx.doi.org/10.1016/0022-3956(75)90026-6] [PMID: 1202204]

[7] Nasreddine ZS, Phillips NA, Bédirian V, et al. The Montreal Cognitive Assessment, MoCA: a brief screening tool for mild cognitive impairment. J Am Geriatr Soc 2005; 53(4): 695-9.

[http://dx.doi.org/10.1111/j.1532-5415.2005.53221.x] [PMID: 15817019]

[8] Ciccarelli R, DAlimonte I, Santavenere C, et al. Cysteinyl-leukotrienes are released from astrocytes and increase astrocyte proliferation and glial fibrillary acidic protein via cys-LT1 receptors and mitogen-activated protein kinase pathway. Eur J Neurosci 2004; $20(6)$ : $1514-24$. [http://dx.doi.org/10.1111/j.1460-9568.2004.03613.x] [PMID: 15355318] 
[9] Zhang YJ, Zhang L, Ye YL, et al. Cysteinyl leukotriene receptors CysLT1 and CysLT2 are upregulated in acute neuronal injury after focal cerebral ischemia in mice. Acta Pharmacol Sin 2006; 27(12): 1553-60. [http://dx.doi.org/10.1111/j.1745-7254.2006.00458.x] [PMID: 17112408]

[10] Wei-Ping Z, Ou-Yang M, Steven A, et al. Generation and growth mechanism of metal (Fe, Co, Ni) nanotube arrays. Neurosci Lett 2004; 363 : 247-51. [PMID: 15182953]

[11] Huang XJ, Zhang WP, Li CT, et al. Activation of CysLT receptors induces astrocyte proliferation and death after oxygen-glucose deprivation. Glia 2008; 56(1): 27-37.

[http://dx.doi.org/10.1002/glia.20588] [PMID: 17910051]

[12] Wang L, Du C, Lv J, Wei W, Cui Y, Xie X. Antiasthmatic drugs targeting the cysteinyl leukotriene receptor 1 alleviate central nervous system inflammatory cell infiltration and pathogenesis of experimental autoimmune encephalomyelitis. J Immunol 2011; 187(5): $2336-45$. [http://dx.doi.org/10.4049/jimmunol.1100333] [PMID: 21804021]

[13] Zhao R, Shi W-Z, Zhang Y-M, et al. Montelukast: much more than an antiasthma drug. J Pharm Pharmacol 2011; 63: 550-7. [http://dx.doi.org/10.1111/j.2042-7158.2010.01238.x] [PMID: 21401607]

[14] Kalonia H, Kumar P, Kumar A, Nehru B. Protective effect of montelukast against quinolinic acid/malonic acid induced neurotoxicity: possible behavioral, biochemical, mitochondrial and tumor necrosis factor- $\alpha$ level alterations in rats. Neuroscience 2010; 171(1): $284-99$. [http://dx.doi.org/10.1016/j.neuroscience.2010.08.039] [PMID: 20813166]

[15] Lai J, Hua M, Wang H, et al. Montelukast targeting the cysteinyl leukotriene receptor 1 ameliorates A $\beta 1-42$-induced memory impairment and neuroinflammatory and apoptotic responses in mice Neuropharmacol 2014; 79(1): 707-14.

\section{(C) Spencer I. Rozin; Licensee Bentham Open}

This is an open access article licensed under the terms of the Creative Commons Attribution-Non-Commercial 4.0 International Public License (CC BY-NC 4.0) (https://creativecommons.org/licenses/by-nc/4.0/legalcode), which permits unrestricted, non-commercial use, distribution and reproduction in any medium, provided the work is properly cited. 